\title{
A Role For The Prefrontal Cortex In Heroin-Seeking After Forced Abstinence By Adult Male Rats But Not Adolescents
}

\author{
James M Doherty', Bradley M Cooke' and Kyle J Frantz*,' \\ 'Neuroscience Institute, Georgia State University, Atlanta, GA, USA
}

Adolescent drug abuse is hypothesized to increase the risk of drug addiction. Yet male rats that self-administer heroin as adolescents show attenuated drug-seeking after abstinence, compared with adults. Here we explore a role for neural activity in the medial prefrontal cortex (mPFC) in age-dependent heroin-seeking. Adolescent (35-day-old at start; adolescent-onset) and adult (86-day-old at start) male rats acquired lever-pressing maintained by heroin using a fixed ratio one reinforcement schedule (0.05 and $0.025 \mathrm{mg} / \mathrm{kg}$ per infusion). Following 12 days of forced abstinence, rats were tested for heroin-seeking over I h by measuring the number of lever presses on the active lever. Unbiased stereology was then used to estimate the number of Fos-ir ${ }^{+}$and Fos-ir ${ }^{-}$neurons in prelimbic and infralimbic mPFC. As before, adolescents and adults self-administered similar amounts of heroin, but subsequent heroin-seeking was attenuated in the younger rats. Similarly, the adolescent-onset group failed to show significant neural activation in the prelimbic or infralimbic mPFC during the heroin-seeking test, whereas the adult-onset heroin self-administration group showed two to six times more Fos-ir ${ }^{+}$neurons than their saline counterparts in both mPFC subregions. Finally, the overall number of neurons in the infralimbic cortex was greater in rats from the adolescent-onset groups than adults. The mPFC may thus have a key role in some age-dependent effects of heroin selfadministration.

Neuropsychopharmacology (2013) 38, 446-454; doi:I0.1038/npp.2012.200; published online 17 October 2012

Keywords: periadolescent; development; opiate; c-Fos; relapse; reinstatement

\section{INTRODUCTION}

Drug use often begins during adolescence (Johnston et al, 2010; SAMHSA, 2012), and early onset of drug abuse has been hypothesized to increase the risk of later drug addiction (Kandel et al, 1992; Palmer et al, 2009). One of the greatest challenges to the treatment of drug addiction is vulnerability to relapse (O'Brien, 1997; Chung and Maisto, 2006). In an animal model of relapse, drug-seeking after abstinence from intravenous (i.v.) drug self-administration can be measured as reinstatement of lever-pressing triggered by contextual cues associated with the drug-taking environment (context-induced), discrete drug-paired cues (cueinduced), or reexposure to the drug itself (drug-primed; reviewed in Shaham et al, 2003). Despite reports suggesting that adolescence is a period of heightened vulnerability to drugs (eg, Spear (2000) and Crews et al (2007) for reviews), we have found that male rats that self-administered heroin, morphine, or cocaine as adolescents exhibit attenuated cue-induced reinstatement of drug-seeking after forced abstinence, compared with rats that self-administered in

*Correspondence: Dr KJ Frantz, Neuroscience Institute, Georgia State University, PO Box 5030, Atlanta, GA 30302-5030, USA, Tel: + I 404413 5338, Fax: + 404413 547I, E-mail: kfrantz@gsu.edu Received 8 May 2012; revised 6 August 2012; accepted 28 August 2012 adulthood (Doherty et al, 2009; Li and Frantz, 2009; Doherty and Frantz, 2012a). This result was independently replicated with cocaine-seeking (Anker and Carroll, 2010). It suggests that adolescent rats are less sensitive to some enduring drug effects, an interpretation supported by age differences in several cocaine- and nicotine-related behaviors (Balda et al, 2006; Kerstetter and Kantak, 2007; Shram et al, 2008), as well as fewer signs and symptoms of drug withdrawal among adolescent rodents compared with adults (Doherty and Frantz, 2012b); Doremus et al, 2003; O'Dell et al, 2006; Hodgson et al, 2009).

To identify the substrates involved in this attenuated drug-seeking among adolescent rats, the present study focused on the medial prefrontal cortex (mPFC), a region involved in reinstatement among adult subjects (Kalivas and Volkow, 2005). Stimulus-induced neural activity can be visualized with the immediate early gene product, Fos (Harlan and Garcia, 1998). Fos expression in the context of drug self-administration predicts neural plasticity (Nestler, 2001), and context- or cue-induced reinstatement of heroinseeking in adult rats elevates mPFC c-fos mRNA (Koya et al, 2006; Kuntz et al, 2008). Thus, the aim of the present study was to test the hypothesis that the extent of MPFC activation during a 1-h heroin-seeking test after forced abstinence from heroin self-administration would be lower among rats that self-administered heroin as adolescents compared with adults. 


\section{MATERIALS AND METHODS}

\section{Subjects}

Male Sprague-Dawley rats (Charles River, Raleigh, NC) arrived at post-natal day (P) $22(n=12)$ or P70-74 $(n=10)$ and were housed in groups of $2-3$ (12 h light/dark cycle, lights off 0700 hours). Behavioral testing occurred at the same time every day (0900-1400 hours). Body weights were recorded daily. All procedures complied with the NIH Guide for Care and Use of Laboratory Animals (seventh edition, 1998) and were approved by the Institutional Animal Care and Use Committee of Georgia State University.

\section{Drugs}

Heroin $\mathrm{HCl}$ (gift from NIDA), Brevital (1\% methohexital sodium; King Pharmaceuticals, Bristol, TN), and Timentin antibiotic (GlaxoSmithKline, Research Triangle Park, NC) were all dissolved in sterile saline and filtered $(0.25-\mu \mathrm{m}$ membrane) before i.v. administration.

\section{Heroin Self-Administration and Heroin-Seeking Procedures}

Equipment. Heroin self-administration was conducted in operant conditioning chambers equipped with two retractable levers (Med Associates, St Albans, VT). Active lever presses delivered infusions via polyethylene tubing to the catheter portal on each subject's back. The i.v. catheters were made as described (Caine et al, 1993), with a shorter length of tubing for adolescents (Shahbazi et al, 2008).

I.v. catheter implantation. Adolescent (P28-29) and adult (P76-81) rats were anesthetized with an isoflurane-oxygen vapor mixture $(1.5-5 \%)$ and were catheterized according to Caine et al (1993) and Shahbazi et al (2008). Rats received the antibiotic timentin $(100 \mathrm{mg} / \mathrm{ml})$ and heparinized saline (30 USP U/ml) every day to deter infection and maintain catheter patency (twice daily for 2 days post surgery). Catheter patency was tested weekly with Brevital. If the catheter was defective, the subject was not included in analysis. Acquisition of lever-pressing commenced 5-7 days after surgery.

Self-administration. Adolescent rats were P35 at the start of behavioral testing (body weight $143 \mathrm{~g} \pm 1.7$ ), and adults were P82-87 (body weight $388 \mathrm{~g} \pm 5.2$ ). In four treatment groups (adolescent-onset saline, $n=6$; adolescent-onset heroin, $n=6$; adult-onset saline, $n=5$; and adult-onset heroin, $n=5$ ), rats spontaneously acquired lever-pressing maintained by heroin (or saline) on a fixed ratio one schedule of reinforcement in 13 sessions over 14 days ( 0.05 and $0.025 \mathrm{mg} / \mathrm{kg}$ per infusion; $3 \mathrm{~h}$ daily sessions). Infusions were signaled by a compound stimulus (cue light above active lever, 5-s burst of white noise, house light off). The infusion volume and duration were adjusted daily based on individual body weight (see Doherty and Frantz (2012a) for details).

Heroin-seeking. After 12 days of forced abstinence in the home cages, we tested heroin-seeking for $1 \mathrm{~h}$ under extinction conditions. Heroin-seeking was defined as responding on the previously active lever (Shalev et al, 2001). The compound stimulus of discrete drug-paired cues was not presented in this test. Thus, measured behavior could be called 'extinction responding in the absence of discrete drug-paired cues'. Although reexposure to the drug selfadministration environment (context) is likely to be the stimulus driving any lever-pressing we might observe in these conditions, our methods differ from those of Shaham et al (2003) that provide precise tests of context-induced reinstatement that involve daily exposure to an alternative environment during forced abstinence (eg, Bossert et al, 2011).

\section{Immunohistochemistry}

Ninety minutes after the start of the heroin-seeking test, rats were anesthetized and intracardially perfused with phosphate buffer $(0.1 \mathrm{M})$, followed by $4 \%$ paraformaldehyde. Brains were removed, postfixed in $4 \%$ paraformaldehyde, and submerged in $30 \%$ phosphate-buffered sucrose before cryosectioning ( $40 \mu \mathrm{m}$, four series). Sections were collected in cryoprotectant and stored at $-20^{\circ} \mathrm{C}$.

Fos-ir detection. Brain sections from every experimental group were processed simultaneously in the same multi-well tissue rack to ensure equal treatment. Immunolabeling for Fos occurred on every eighth section through the rostrocaudal extent of the prelimbic and infralimbic MPFC, as well as a portion of the primary motor cortex (M1). We chose $\mathrm{M} 1$ as an anatomical control because motor cortex has not been implicated as a region with selective control of drugseeking. Sections were incubated with anti-Fos antibody for $48 \mathrm{~h}$ at $4{ }^{\circ} \mathrm{C}$ (1:500 rabbit anti-Fos; Santa Cruz Biotechnology, Santa Cruz, CA), followed by biotinylated secondary antibody incubation for $1.5 \mathrm{~h}(1: 600$; Vector Laboratories, Burlingame, $C A)$. Fos was visualized with an $A B C$ kit followed by cobalt-enhanced 3,3'-diaminobenzidine tetrahydrochloride. Nonspecific staining was uniformly low. Sections were mounted on coded, gelatin-coated slides, dehydrated, counter-stained with cresyl violet, cleared with xylene, and coverslipped with permount.

\section{Stereological Analysis of Fos-ir Neurons}

Following Cooke (2011), the total number of Fos-ir ${ }^{+}$and Fos-ir ${ }^{-}$neurons was estimated with the optical fractionator probe in StereoInvestigator (MBF Biosciences, Williston, VT) by a researcher blind to experimental groups. Contours of the prelimbic and infralimbic areas, and a central portion of M1, were traced in one hemisphere at $\times 2.5$ magnification. These contours were used to estimate the regional volume of each area according to the formula:

$$
V=T x\left(\sum A_{1-m}\right)
$$

Where $T=$ average section thickness, $x=$ sectioning ratio, and $A_{1-m}=$ areas of the traced contours. Neurons were counted at $\times 100$ under brightfield illumination using the standard rules with regard to inclusion (Mouton, 2002; see Table 1) on six sections per hemisphere for the 
Table I Parameters for Stereological Analysis of Cortical Neurons

\begin{tabular}{|c|c|c|c|}
\hline & \multicolumn{3}{|c|}{ Brain area } \\
\hline & Prelimbic & Infralimbic & MI \\
\hline Counting sites per rat & $228 \pm 3$ & $65 \pm 2$ & $77 \pm 0.3$ \\
\hline Counting sites per section ( \pm SEM) & $38 \pm 0.5$ & $22 \pm 0.6$ & $25 \pm 0.5$ \\
\hline Average coefficient of error (Gunderson, $m=1$ ) for all rats & $0.07 \pm 0.001$ & $0.14 \pm 0.003$ & $0.14 \pm 0.00$ \\
\hline Counting frame size $\left(\mu \mathrm{m}^{2}\right)$ & 625 & 625 & 625 \\
\hline Virtual $x-y$ sampling grid size $(\mu \mathrm{m})$ & $155 \times 184$ & $155 \times 184$ & $155 \times 184$ \\
\hline Counting frame height $(\mu \mathrm{m})$ & 8 & 8 & 8 \\
\hline Guard zone $(\mu \mathrm{m})$ & 2 & 2 & 2 \\
\hline
\end{tabular}
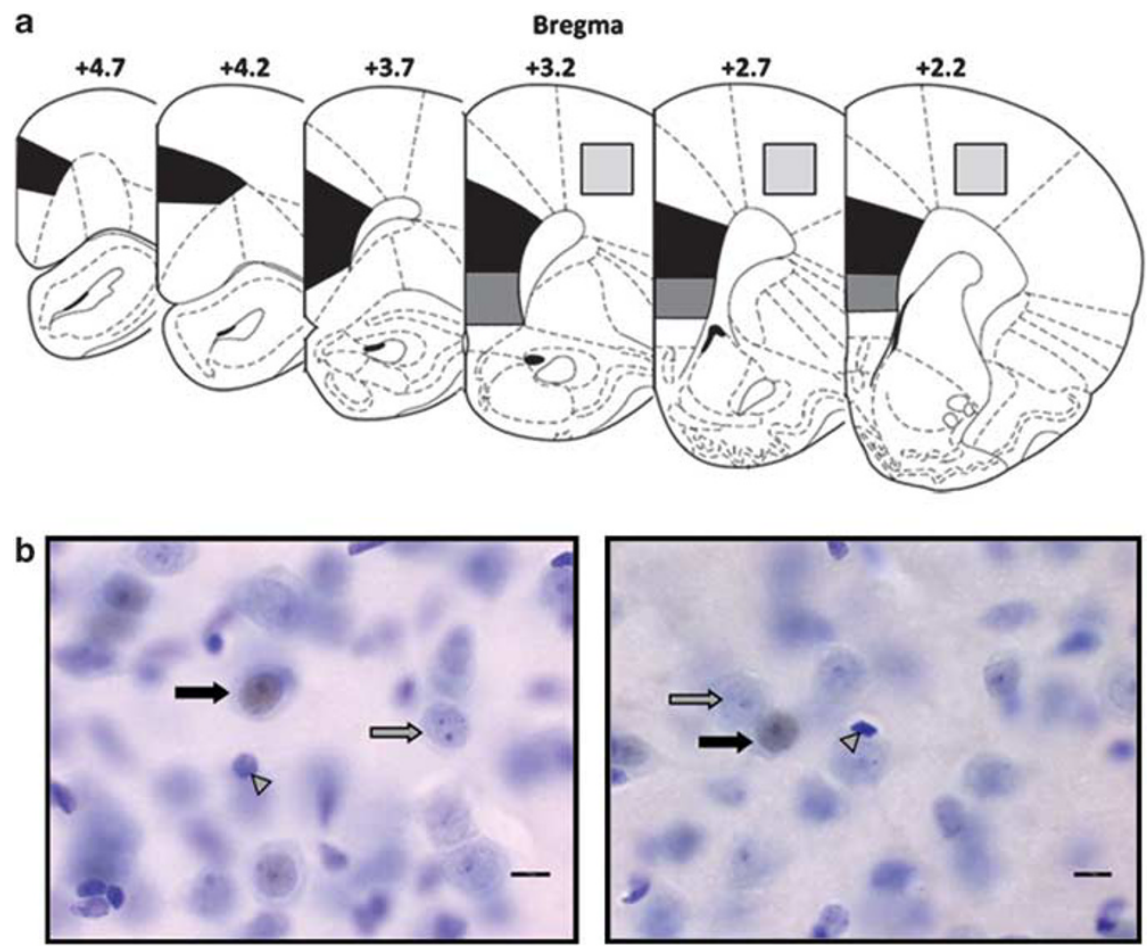

Figure I (a). Neurons were counted in the prelimbic (black), infralimbic (dark gray), and MI (light gray) cortices. (b). Photomicrographs at $\times$ I00 of prelimbic (left) and infralimbic (right) neurons, indicating Fos-ir ${ }^{+}$neurons (black arrows), Fos-ir ${ }^{-}$neurons (gray arrows), and glial cells (gray triangles). Scale bar $=10 \mu \mathrm{m}$.

prelimbic area (estimated at $4.7,4.2,3.7,3.2,2.7$, and $2.2 \mathrm{~mm}$ anterior to bregma; plates 5-10 in Paxinos and Watson (1998)), and three sections for infralimbic and M1 areas $(3.2,2.7$, and $2.2 \mathrm{~mm}$ anterior to bregma; plates $8-10$; Figure 1a). This scheme resulted in an equivalent number of neurons counted in each age group. Fos-ir ${ }^{+}$neurons possessed dark-brown cytoplasm and black nuclei, whereas Fos-ir ${ }^{-}$neurons possessed light-violet clear cytoplasm and dark-violet nuclei (Figure 1b). The estimated number of neurons, $E(N)$ was calculated according to the formula:

$$
E(N)=\sum Q^{-}(1 / s s f \times 1 / \operatorname{asf} \times 1 / t s f)
$$

Where $Q^{-}=$number of counted cells, $s s f=$ section sampling fraction, $a s f=$ area sampling fraction, and $t s f=$ thickness sampling fraction. 


\section{Data Analysis}

Heroin self-administration. Intake and lever presses were analyzed separately using mixed-measures analysis of variance (ANOVA) with age (adolescent $v s$ adult) and treatment (heroin $v s$ saline self-administration) as betweensubjects factors, and session, dose (0.05 vs $0.025 \mathrm{mg} / \mathrm{kg}$ per infusion), and lever (active $v s$ inactive) as within-subjects repeated measures. Total heroin intake was compared across age groups using $t$-tests.

Heroin-seeking. Lever presses during the 1-h heroinseeking test were analyzed using a three-way ANOVA, with age and treatment as between-subjects factors, and lever as the within-subjects factor. In addition, responding on the active lever in heroin-treatment groups was expressed relative to active lever responding in age-matched saline controls (fold change from saline), then compared with t-tests.

Fos-ir. Estimates of total neuron number in prelimbic, infralimbic, and M1 were analyzed separately using two-way ANOVAs, with age and treatment as between-subjects factors. The percentage of Fos-ir ${ }^{+}$to total neurons in each brain region was calculated and tested for normality. Distributions were non-normal in IL and M1, so these data were log transformed before further analysis, which consisted of two-way ANOVAs, with age and treatment as between-subjects factors. Fos-ir expression across the rostro-caudal axis was compared by calculating the fold change in Fos-ir ${ }^{+}$expression in heroin- $v s$ saline-treated rats. A two-way ANOVA tested for differences across age (between-subjects factor) and bregma level (within-subjects repeated measure).

To compare neuronal activation across brain regions, data from all brain regions were log transformed and fold change of Fos-ir ${ }^{+}$from saline was analyzed using a twoway mixed-measures ANOVA, with age as a betweensubjects factor and brain region as a within-subjects factor, at the three rostro-caudal levels at which all three brain regions were analyzed. Data were analyzed using SPSS (SPSS, Chicago, IL) and expressed as means \pm SEM. In all cases, follow-up ANOVAs and post-hoc tests were conducted as appropriate, with $P<0.05$ considered significant.

\section{RESULTS}

Heroin self-administration. Adolescent and adult rats self-administered similar amounts of heroin, with similar patterns of acquisition (Figure 2). As expected, the number of infusions per session differed according to drug treatment $\left(\mathrm{F}_{1,18}=24.7, P<0.001\right)$, session $\left(\mathrm{F}_{12,216}=6.4, P<0.001\right)$, and a treatment-by-session interaction $\left(\mathrm{F}_{12,216}=14.8, P<0.001\right)$, but there was no main effect of age nor interactions with age. Heroin intake increased gradually across sessions, and rats self-administering heroin earned more infusions than those receiving saline, especially in the second week. Regardless of age, when the dose per infusion was decreased, heroin infusions per session increased (main effect of dose, $F_{1,9}=38.2$, $P<0.001)$. Furthermore, heroin intake $(\mathrm{mg} / \mathrm{kg})$ did not differ by age (Figure 2, inset).

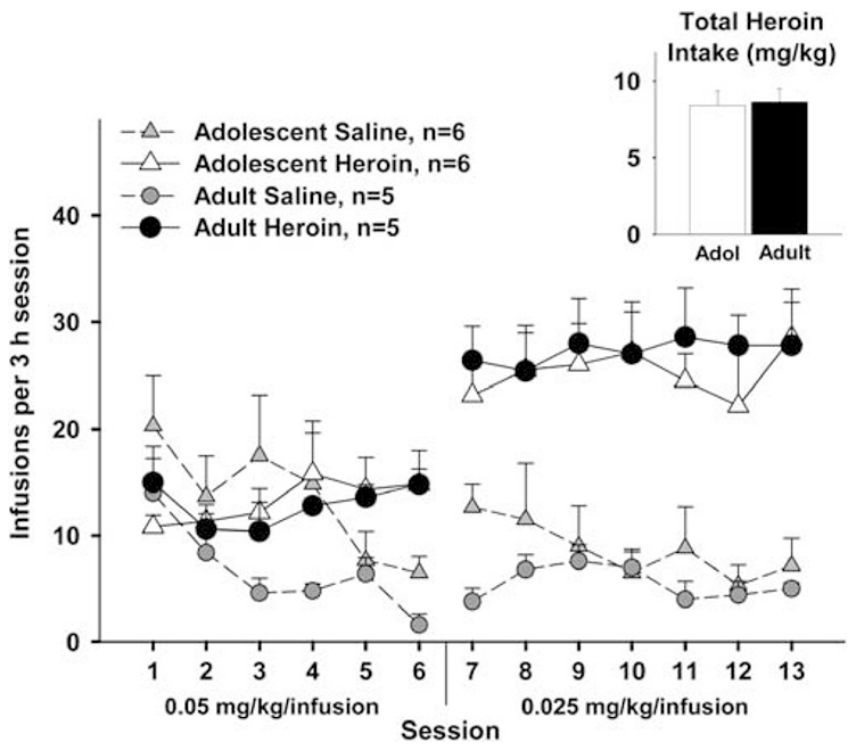

Figure 2 Infusions of heroin or saline on a fixed ratio one schedule of reinforcement. Inset: total heroin intake $(\mathrm{mg} / \mathrm{kg}$ ) by adolescent (Adol) or adult rats. All points and bars represent mean \pm SEM.

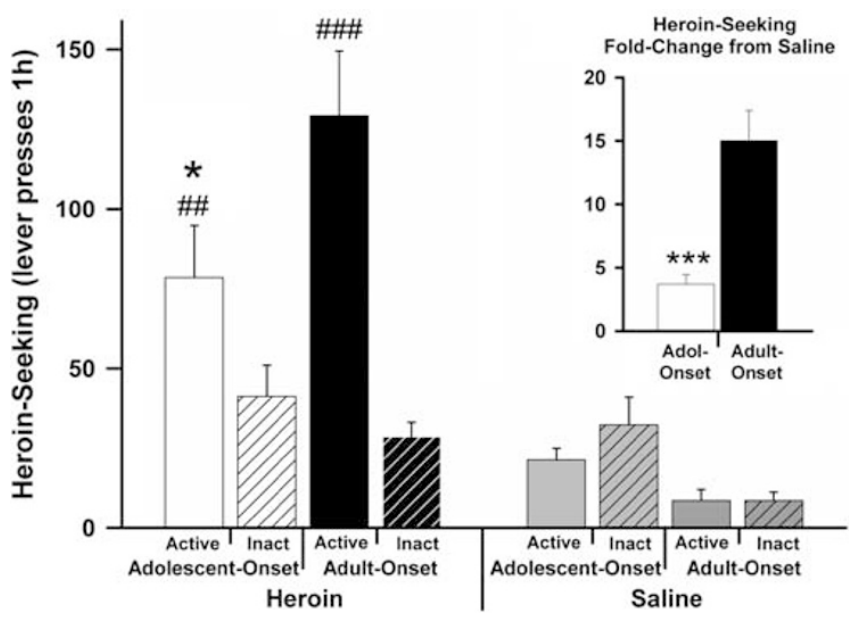

Figure 3 Active and inactive lever presses during a I-h heroin-seeking test. Heroin-treated rats pressed on the active lever more than the inactive

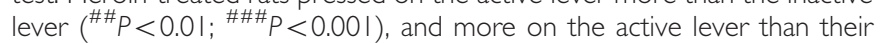
saline-treated counterparts. The adolescent-onset heroin group pressed less on the active lever than the adult-onset heroin group ( $\left.{ }^{*} P<0.05\right)$. Inset: relative heroin-seeking was attenuated in the adolescent-onset groups, compared with adults $\left({ }^{* * *} P<0.001\right)$. For adolescent saline, adolescent heroin, adult saline, and adult heroin-treatment groups, $n=6,6,5$, and 5 , respectively. All bars represent mean \pm SEM.

Heroin-seeking after forced abstinence. Rats that selfadministered heroin as adolescents (adolescent-onset group) exhibited less heroin-seeking after abstinence than adults, although all rats that self-administered heroin exhibited more lever-pressing after abstinence than their saline-treated counterparts (Figure 3). A three-way ANOVA confirmed that lever-pressing differed according to treatment $\left(\mathrm{F}_{1,18}=39.02, P<0.001\right)$ and lever $\left(\mathrm{F}_{1,18}=21.83\right.$, $P<0.001)$, and that adolescent-onset groups pressed the active lever less than adults (age-by-lever interaction, 
$\left.\mathrm{F}_{1,18}=7.47, P<0.05\right)$. A follow-up two-way ANOVA on active lever-pressing confirmed a significant age-by-treatment interaction $\left(\mathrm{F}_{1,18}=5.87, P<0.05\right)$; and among those rats that self-administered heroin, the adolescent-onset group pressed fewer times on the active lever than adults $(P<0.05)$, and heroin-experienced rats pressed more than saline controls (adolescent onset: $P<0.01$; adult onset: $P<0.001)$. When active lever-pressing was analyzed as a fold change among heroin groups $v s$ saline controls, relative responding was attenuated in adolescent-onset compared with adult-onset groups $(P<0.001$; Figure 3 , inset $)$.

Prelimbic Fos-ir. Heroin-seeking was associated with a greater percentage of Fos-ir ${ }^{+}$neurons in the prelimbic cortex of adult-onset groups compared with their salinetreated counterparts, but no difference in FOS expression was observed in adolescence-onset heroin groups $v s$ controls. These results were supported by a two-way ANOVA on the percentage of prelimbic Fos-ir ${ }^{+}$to total neurons, showing a significant interaction of age-by-treatment $\left(\mathrm{F}_{1,18}=7.1, P<0.05\right)$; post-hoc Tukey's pairwise comparisons confirmed a significant treatment effect in the adultonset groups $(P<0.01)$. When the percentage of Fos-ir ${ }^{+}$ neurons to total was expressed as a fold change from saline, the adult-onset heroin group exhibited more Fos-ir ${ }^{+}$neurons than the adolescent-onset heroin group, particularly toward the caudal pole of prelimbic area (Figure 4g; age-by-rostrocaudal level interaction, $\left.\mathrm{F}_{5,45}=3.13, P<0.05\right)$, and followup independent samples $t$-tests (with Bonferroni's correction) at each level confirmed that the adult-onset group had more Fos-ir ${ }^{+}$neurons at levels estimated to be $3.7-2.2 \mathrm{~mm}$ anterior to bregma $(P<0.05)$.

Infralimbic Fos-ir. Regardless of drug treatment, the total estimated number of neurons (Fos-ir ${ }^{+}$plus Fos-ir ${ }^{-}$) in the infralimbic area was higher for adolescent-onset compared with adult-onset groups (main effect of age: $F_{1,18}=16.56$, $P<0.001$; Figure $4 \mathrm{~b}$ ). As in the prelimbic cortex, more neurons were Fos-ir ${ }^{+}$in the infralimbic area of the adultonset heroin group compared with their saline counterparts, an effect not observed in the adolescent-onset groups (log-transformed data; Figure 4e). This was confirmed by a significant interaction of age-by-treatment $\left(\mathrm{F}_{1,18}=7.60\right.$, $P<0.05)$, leading to a significant age effect within groups that self-administered heroin $(P<0.01)$, and a treatment effect within adult-onset groups $(P<0.05)$. When the percentage of Fos-ir ${ }^{+}$neurons to total was expressed as a fold change from saline, a significant interaction of age-byrostro-caudal level $\left(\mathrm{F}_{2,18}=4.37, P<0.05\right)$ led to follow-up independent-sample $t$-tests (with Bonferroni's correction) at each rostro-caudal level to confirm that the adult-onset group had more Fos-ir ${ }^{+}$neurons at each level $(P<0.05$; Figure $4 \mathrm{~h})$. Within the adult group, a one-way ANOVA on rostro-caudal level was significant $\left(\mathrm{F}_{2,8}=29.71, P<0.001\right)$, and Bonferroi-corrected paired-samples $t$-tests confirmed that $\mathrm{Fos}_{-\mathrm{ir}}{ }^{+}$was greater at +2.7 than at other levels $(P<0.01)$.

M1 Fos-ir. The log-transformed percentage of Fos-ir ${ }^{+}$to total neurons in M1 did not differ by age group or drug treatment (Figure 4c,f). It follows that the percentage of
Fos-ir ${ }^{+}$neurons to total, expressed relative to saline counterparts, did not differ by age, although one rat in the adolescent heroin group had more Fos-ir ${ }^{+}$neurons than his counterparts, thereby raising the group means at rostro-caudal levels estimated to be at 3.2 and $2.2 \mathrm{~mm}$ anterior to bregma (Figure 4i).

Comparison of Fos-ir across brain regions. With the percentage of Fos-ir ${ }^{+}$neurons to total among heroin groups expressed as a fold change from saline (and log transformed), neuronal activation was compared across brain regions at levels estimated to be $3.2,2.7$, or $2.2 \mathrm{~mm}$ anterior to bregma (Figure $4 \mathrm{~g}, \mathrm{~h}$, and i). At approximately +3.2 , differences across age and brain region were observed, such that a significant age-by-brain region interaction occurred $\left(\mathrm{F}_{2,18}=4.55, \quad P=0.025\right)$. Although neuronal activation among adolescents did not differ by brain region, differences occurred in adults, such that a follow-up one-way ANOVA across brain regions was significant $\left(\mathrm{F}_{2,8}=10.30, P=0.006\right)$. Specifically, IL activation was greater than $\mathrm{M} 1$ activation, according to follow-up $t$-tests with Bonferroni's correction $(P<0.05)$. At +2.7 , differences across age and brain region were also observed, such that a two-way age-by-brain region ANOVA included significant main effects of age $\left(\mathrm{F}_{1,9}=13.29, P<0.01\right)$ and brain region $\left(\mathrm{F}_{2,18}=12.29, P<0.001\right)$, as well as a significant interaction $\left(\mathrm{F}_{2,18}=5.90, P<0.05\right)$. As at +3.2 , neuronal activation did not differ across brain regions in adolescents, but a follow-up one-way ANOVA across brain regions was significant for adults $\left(\mathrm{F}_{2,8}=10.54, P<0.01\right)$. Specifically, activation was greater in the infralimbic region than prelimbic or M1 areas, according to $t$-tests with Bonferroni's correction $(P<0.05)$. At approximately +2.2 , no age or brain region differences were observed.

\section{DISCUSSION}

Despite similar levels of heroin self-administration by adolescent and adult male rats, the younger age group showed less heroin-seeking after 12 days of forced abstinence. This adolescent-onset group also failed to show significant neural activation in the prelimbic or infralimbic mPFC during the heroin-seeking test, whereas the adultonset heroin self-administration group showed two to six times more Fos-ir ${ }^{+}$neurons than their saline counterparts in both $\mathrm{mPFC}$ subregions. These results suggest that activation of the $\mathrm{MPFC}$ may mediate drug-seeking in rats that initiated self-administration during adulthood, but not adolescence. In addition, the estimated total number of neurons in the infralimbic cortex was greater in younger $v s$ older subjects, regardless of drug treatment.

In the present experiment, both adolescent and adult rats acquired and maintained heroin self-administration. Relatively stable numbers of infusions earned by both adolescents and adults in heroin self-administration groups contrast with the gradual decline in infusions earned by saline control groups. Moreover, when the heroin dose was reduced by half, the number of infusions earned almost doubled, confirming that heroin reinforced lever-pressing. Although no age differences in the number of heroin infusions per session were observed in the present experiment, we reported slightly higher rates of heroin 


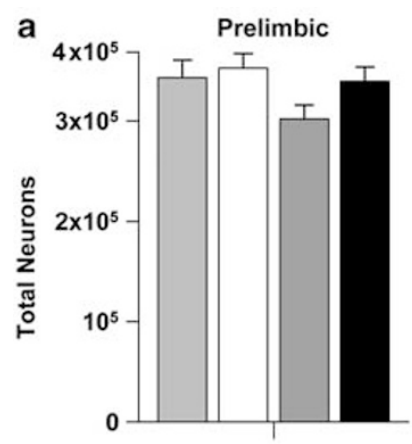

d

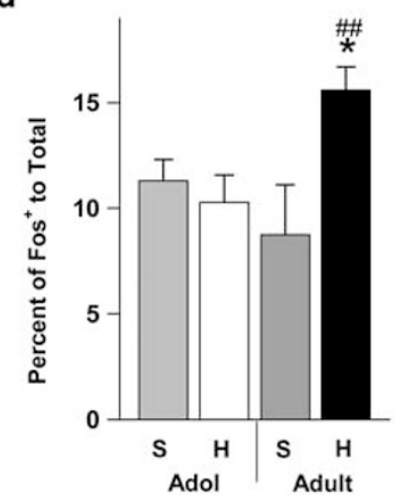

g

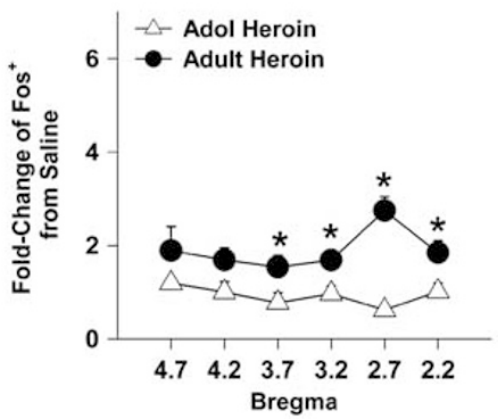

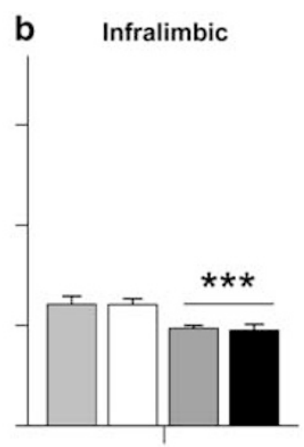
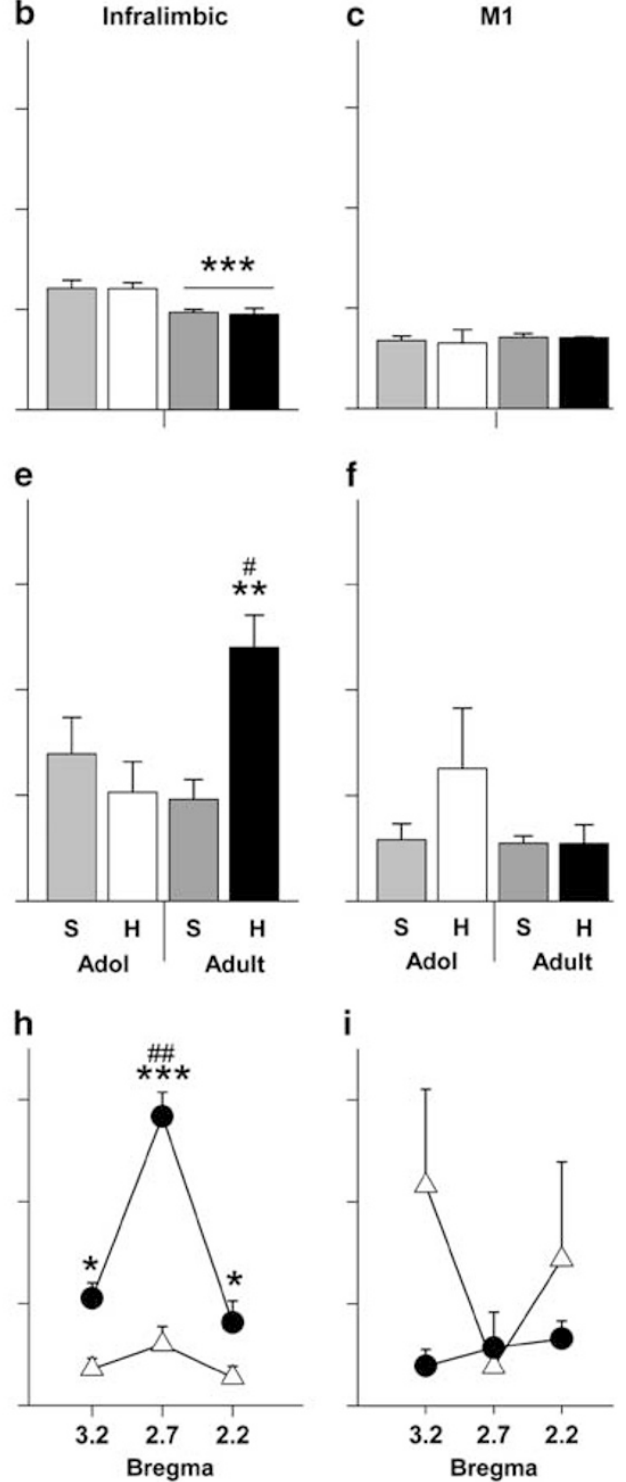

Figure $4(\mathrm{a}-\mathrm{c})$. Neuron number in prelimbic, infralimbic, and $\mathrm{MI}$ cortices. Adolescent-onset groups (P6I) had more neurons than adult-onset groups (PI07-1 I2) in infralimbic, but not prelimbic or MI. ( $d-f)$. The adolescent-onset heroin group had a lower percentage of Fos-ir ${ }^{+}$neurons than adults, in prelimbic (d) and infralimbic (e) areas (*). In contrast, the adult-onset heroin group had more Fos-ir ${ }^{+}$neurons than saline controls in prelimbic (d) and infralimbic (e) areas (\#). (g-i): Fold change in relative number of Fos-ir ${ }^{+}$neurons in heroin-seeking rats compared with their saline controls in prelimbic, infralimbic, and $\mathrm{MI}$ areas, expressed as a function of rostro-caudal level, with less Fos labeling in the adolescent-onset group than adults (*). Also in the infralimbic area of adult rats $(h)$, the number of Fos-ir ${ }^{+}$neurons was higher at +2.7 bregma than the other rostro-caudal levels (\#\#). For adolescent saline, adolescent heroin, adult saline, and adult heroin-treatment groups, $n=6,6,5$, and 5, respectively. All bars and points in a-i represent mean \pm SEM ( ${ }^{*}, \# P<0.05$; ${ }^{* *}, \# \# P<0.01$; ${ }^{* * * *} P<0.001$ ).

self-administration among adolescents compared with adults in a previous experiment (Doherty and Frantz, 2012a). Inconsistent patterns of self-administration have prompted us to question the reliability of age differences in the acutely reinforcing effects of opiates in the selfadministration procedure (Doherty and Frantz, 2012a).

What has remained consistent across our studies of heroin, morphine, and cocaine self-administration, however, is that male rats that initiate drug self-administration during adolescence exhibit attenuated drug-seeking after forced abstinence compared with rats that initiate selfadministration during adulthood (Doherty et al, 2009; Li and Frantz, 2009; Doherty and Frantz, 2012a). Our studies reveal attenuated responsivity among younger rats on measures of extinction responding in the absence of discrete drug-paired cues (as in the present study), and cueinduced reinstatement after extinction (see references above). Given that the compound stimulus of discrete drug-paired cues was not included in the present test of drug-seeking, reexposure to the drug self-administration environment (context) is likely the stimulus driving the lever-pressing we observed. These results are consistent with less robust cue-induced reinstatement of cocaineseeking observed over a shorter experimental time course (Anker and Carroll, 2010); and with reports of faster extinction and less reinstatement of a cocaine-conditioned place preference among adolescents $v s$ adults (Balda $e t a l$, 2006, but see Brenhouse et al, 2008), as well as faster 
extinction of nicotine-seeking (Shram et al, 2008) and less nicotine-paired cue-conditioning among adolescent $v s$ adult rats (Schochet et al, 2004). Cognitive impairment on an amydgala-dependent task after cocaine intake (but not an orbitofrontal cortex-dependent task) is also less severe in younger rats (Harvey et al, 2009; Kerstetter and Kantak, 2007). In further support of reduced enduring effects of heroin in adolescent rats compared with adults, somatic and locomotor signs of spontaneous withdrawal from repeated systemic heroin injections are attenuated, as are the effects of heroin on body weight and food intake (Doherty and Frantz, 2012b). Similarly, fewer affective and/or somatic signs of withdrawal from heroin, morphine, nicotine, or alcohol adolescent rodents as compared with adults (eg, Doherty and Frantz, 2012b; Doremus et al, 2003; O'Dell et al, 2006; Hodgson et al, 2009). Although several studies suggest greater sensitivity among adolescent subjects (or adolescent-onset groups), a growing body of literature suggests that adolescence may be associated with protection from some acute and enduring effects of drug exposure under certain conditions. The parameters that define those conditions, however, remain to be determined.

Given the present replication of the finding that adolescent-onset groups exhibit less robust heroin-seeking after forced abstinence than adults, we went on to examine neural activation in the mPFC. Using Fos immunohistochemistry to mark activated neurons, and stereological techniques to estimate total numbers of $\mathrm{Fos}_{-} \mathrm{ir}^{+}$and Fos-ir ${ }^{-}$neurons, we confirmed earlier reports that overall neuron number declines with age in the ventral mPFC (Andersen et al, 2000; Markham et al, 2007). Reductions in both cell number and cortical volume occur during the transition from adolescence into adulthood in rodents, nonhuman primates, and humans (Sowell et al, 1999; Andersen et al, 2000; Markham et al, 2007). Our differentiation of the $\mathrm{mPFC}$ into prelimbic and infralimbic regions revealed that the reduction in ventral mPFC cell number between P35 and P90 reported by Markham et al, (2007) may be specific to the infralimbic cortex, and that it does not occur until after P61. Anatomical changes during adolescence correlate with emergence of adult-like executive and decision-making behaviors (Ernst and Fudge, 2009), but their role in drugseeking, if any, remains to be determined.

Our observation that Fos activation was greater in the infralimbic than prelimbic cortex of adult rats during heroin-seeking is consistent with a greater role for the infralimbic than prelimbic region in heroin-seeking (Van den Oever et al, 2008; Bossert et al, 2011), but contradicts theories based mainly on cocaine-related behavior that the infralimbic cortex inhibits drug-seeking, whereas the prelimbic cortex promotes it (Peters et al, 2009). For both subregions, we also observed activation in only a small percentage of neurons during heroin-seeking, similar to the 5-7\% activation reported previously (Bossert et al, 2011). Together with the aforementioned confirmation of agerelated declines in neuron number, these similarities across data sets help to validate the present methodology.

The major finding of the present report is an attenuated mPFC activation during heroin-seeking among rats that self-administered heroin as adolescents, compared with adults. The percentage of Fos-ir ${ }^{+}$neurons in the adolescent-onset heroin group did not differ from age-matched saline controls, whereas the adult-onset heroin group exhibited a two- to six-fold increase in $\mathrm{Fos}_{-} \mathrm{ir}^{+}$neurons relative to their controls. The most robust effects occurred at approximately $2.7 \mathrm{~mm}$ anterior to bregma. Lower levels of drug-related Fos-ir in adolescents $v s$ adults differs from reports that experimenter-administered nicotine or cocaine acutely elevates $c$-fos mRNA expression in the mPFC more among younger than older male rats (Schochet et al, 2005; Shram et al, 2007; Cao et al, 2007; Caster and Kuhn, 2009), but self-administration often produces results different from experimenter administration (eg, Robinson et al, 2002). Our results suggest that the mPFC may have a key role in age-dependent enduring effects of heroin selfadministration in male rats.

In fact, several lines of evidence support a critical role for the $\mathrm{mPFC}$ in age-dependent drug-related behavior. For example, targeted inhibition of Fos-activated neurons in either the prelimbic or infralimbic region reduces heroinseeking after forced abstinence in adult male rats (Bossert et al, 2011), showing that activation of these neurons is a cause and not a consequence of drug-seeking. Furthermore, the $\mathrm{mPFC}$ undergoes significant plasticity during adolescence, making it a good candidate to mediate behaviors that change over the same developmental phase (eg, Spear, 2000; Adriani and Laviola, 2004; Lenroot and Giedd, 2006). Yet, much remains to be addressed in this line of investigation. Although both glutamatergic and GABAergic cells in prelimbic and infralimbic cortex are implicated in heroinseeking by adult rats (Bossert et al, 2011), double-labeling experiments are necessary to delineate which cell types are differentially activated across age groups, ie, which cells are involved in the enduring motivational salience of drugassociated cues after self-administration during adolescence. Significant changes occur in both glutamatergic and GABAergic cells during adolescence (eg, Andersen et al, 2000; Tseng and O'Donnell, 2007; Brenhouse et al, 2008), potentially contributing to phenomena such as reduced cortical inhibition and coordination in adolescents compared with adults (Sturman and Moghaddam, 2011). Some cells altered by drug intake during adolescence could undergo apoptosis during the transition from adolescence to adulthood, thereby minimizing the enduring effects of early drug exposure. Along these lines, D1 dopamine receptors expressed on glutamatergic projection neurons in the mPFC appear to process the salience of drugassociated contextual cues during reinstatement tests (Brenhouse et al, 2010); thus, a natural decline in D1 receptor expression after adolescence (Andersen et al, 2000; Brenhouse et al, 2008) could also contribute to a loss of salience of drug-associated cues, be they contextual cues or discrete cues paired with drug self-infusions. Resolution between studies like ours demonstrating adolescent resistance to drug effects $v s$ those demonstrating heightened drug sensitivity among adolescents may relate to the duration of drug exposure (eg, whether it ceases during adolescence or continues into adulthood), the intensity of drug exposure (eg, drug doses), and/or the parameters for testing drug effects. For example, we observed similar rates of reinstatement among adolescent- and adult-onset groups when both context and cues were renewed simultaneously (Doherty and Frantz, 2012a). Also, extinction of a cocaineconditioned place preference occurred at the same rate 
in adolescent and adult rats when explicit extinction procedures were used (Brenhouse et al, 2010), and the age-dependent effects of cocaine self-administration on cognition vary by which brain region mediates the cognitive task (Kerstetter and Kantak, 2007; Harvey et al, 2009). These latter studies underscore the idea that different mechanisms may mediate extinction responding, context-induced reinstatement, and cue-induced reinstatement of drugseeking. They may also provide experimental conditions in which to test for these different mechanisms.

Overall, attenuated neuronal activity in the prelimbic and infralimbic areas of the MPFC during heroin-seeking in the adolescent-onset group supports and extends our previous reports on attenuated enduring effects of heroin, morphine, and cocaine on drug-seeking after forced abstinence among young rats (Doherty et al, 2009; Li and Frantz, 2009; Doherty and Frantz, 2012a). Although translation of results from rodents to humans requires extensive research, adolescent male rats may provide a natural model from which neuroprotective factors against long-term drug effects can be identified, thereby providing new targets for the treatment of drug abuse in humans.

\section{ACKNOWLEDGEMENTS}

The authors acknowledge Jill Weathington, Chen Li, Bonnie Williams, Patrick Dunigan, and Adria Lee for their excellent technical assistance. This research was supported in part by the NIH (1 RO3 DA020110-01 to KJF), the Center for Behavioral Neuroscience NSF Science and Technology Center (IBN-9876754), and the Brains and Behavior Program at Georgia State University. JMD is currently affiliated with the Waggoner Center for Alcohol and Addiction Research, College of Pharmacy, Department of Pharmacology, University of Texas at Austin.

\section{DISCLOSURE}

The authors declare no conflict of interest.

\section{REFERENCES}

Adriani W, Laviola G (2004). Windows of vulnerability to psychopathology and therapeutic strategy in the adolescent rodent model. Behav Pharmacol 15: 341-352.

Andersen SL, Thompson AT, Rutstein M, Hostetter JC, Teicher MH (2000). Dopamine receptor pruning in prefrontal cortex during the periadolescent period in rats. Synapse 37: 167-169.

Anker J, Carroll M (2010). Reinstatement of cocaine seeking induced by drugs, cues, and stress in adolescent and adult rats. Psychopharmacology (Berl) 208: 211-222.

Balda M, Anderson K, Itzhak Y (2006). Adolescent and adult responsiveness to the incentive value of cocaine reward in mice: role of neuronal nitric oxide synthase (nNOS) gene. Neuropharmacology 51: 341-349.

Bossert J, Stern A, Theberge FRM, Cifani C, Koya E, Hope B et al (2011). Ventral medial prefrontal cortex neuronal ensembles mediate context-induced relapse to heroin. Nat Neurosci 14: 420-422.

Brenhouse H, Sonntag K, Andersen S (2008). Transient D1 dopamine receptor expression on prefrontal cortex projection neurons: relationship to enhanced motivational salience of drug cues in adolescence. J Neurosci 28: 2375-2382.
Brenhouse HC, Dumais K, Andersen SL (2010). Enhancing the salience of dullness: behavioral and pharmacological strategies to facilitate extinction of drug-cue associations in adolescent rats. Neuroscience 169: 628-636.

Caine S, Lintz R, Koob G(eds) (1993). Intravenous drug-self-administration techniques in animals. Oxford University Press: New York, NY.

Cao J, Lotfipour S, Loughlin S, Leslie F (2007). Adolescent maturation of cocaine-sensitive neural mechanisms. Neuropsychopharmacology 32: 2279-2289.

Caster JM, Kuhn CM (2009). Maturation of coordinated immediate early gene expression by cocaine during adolescence. Neuroscience 160: 13-31.

Chung T, Maisto SA (2006). Relapse to alcohol and other drug use in treated adolescents: review and reconsideration of relapse as a change point in clinical course. Clin Psychol Rev 26: 149-161.

Cooke BM (2011). Synaptic reorganisation of the medial amygdala during puberty. J Neuroendocrinol 23: 65-73.

Crews F, He J, Hodge C (2007). Adolescent cortical development: a critical period of vulnerability for addiction. Pharmacol Biochem Behav 86: 189-199.

Doherty J, Frantz K (2012a). Heroin self-administration and reinstatement of heroin-seeking in adolescent $v s$. adult male rats. Psychopharmacology (Berl) 219: 763-773.

Doherty J, Frantz K (2012b). Attenuated effects of experimenteradministered heroin in adolescent vs. adult male rats: physical withdrawal and locomotor sensitization. Psychopharmacology (Berl); e-pub ahead of print 2 September 2012.

Doherty J, Ogbomnwan Y, Williams B, Frantz K (2009). Agedependent morphine intake and cue-induced reinstatement, but not escalation in intake, by adolescent and adult male rats. Pharmacol Biochem Behav 92: 164-172.

Doremus TL, Brunell SC, Varlinskaya EI, Spear LP (2003). Anxiogenic effects during withdrawal from acute ethanol in adolescent and adult rats. Pharmacol Biochem Behav 75: 411-418.

Ernst M, Fudge JL (2009). A developmental neurobiological model of motivated behavior: Anatomy, connectivity and ontogeny of the triadic nodes. Neurosci Biobehav Rev 33: 367-382.

Harlan RE, Garcia MM (1998). Drugs of abuse and immediateearly genes in the forebrain. Mol Neurobiol 16: 221-267.

Harvey R, Dembro K, Rajagopalan K, Mutebi M, Kantak K (2009). Effects of self-administered cocaine in adolescent and adult male rats on orbitofrontal cortex-related neurocognitive functioning. Psychopharmacology (Berl) 206: 61-71.

Hodgson SR, Hofford RS, Wellman PJ, Eitan S (2009). Different affective response to opioid withdrawal in adolescent and adult mice. Life Sci 84: 52-60.

Johnston LD, O’Malley PM, Bachman JG, Schulenberg JE (2010). Monitoring the Future national results on adolescent drug use: overview of key findings, 2009. NIH Publication No 10-7583.

Kalivas P, Volkow N (2005). The neural basis of addiction: a pathology of motivation and choice. Am J Psychiatry 162: 1403-1413.

Kandel DB, Yamaguchi K, Chen K (1992). Stages of progression in drug involvement from adolescence to adulthood: further evidence for the gateway theory. J Stud Alcohol 53: 447-457.

Kerstetter KA, Kantak KM (2007). Differential effects of selfadministered cocaine in adolescent and adult rats on stimulusreward learning. Psychopharmacology (Berl) 194: 403-411.

Koya E, Spijker S, Voorn P, Binnekade R, Schmidt ED, Schoffelmeer AN et al (2006). Enhanced cortical and accumbal molecular reactivity associated with conditioned heroin, but not sucrose-seeking behaviour. J Neurochem 98: 905-915.

Kuntz K, Patel K, Grigson P, Freeman W, Vrana K (2008). Heroin self-administration: II. CNS gene expression following withdrawal and cue-induced drug-seeking behavior. Pharmacol Biochem Behav 90: 349-356.

Lenroot R, Giedd J (2006). Brain development in children and adolescents: insights from anatomical magnetic resonance imaging. Neurosci Biobehav Rev 30: 718-729. 
Li C, Frantz KJ (2009). Attenuated incubation of cocaine seeking in male rats trained to self-administer cocaine during periadolescence. Psychopharmacology (Berl) 204: 725-733.

Markham JA, Morris JR, Juraska JM (2007). Neuron number decreases in the rat ventral, but not dorsal, medial prefrontal cortex between adolescence and adulthood. Neuroscience 144: 961-968.

Mouton P (2002). The Principles and Practices of Unbiased Stereology: An Introduction for Bioscientists. Johns Hopkins University Press: Baltimore, MD.

Nestler EJ (2001). Molecular basis of long-term plasticity underlying addiction. Nature Rev Neurosci 2: 119-128.

O'Dell LE, Bruijnzeel AW, Smith RT, Parsons LH, Merves ML, Goldberger BA et al (2006). Diminished nicotine withdrawal in adolescent rats: implications for vulnerability to addiction. Psychopharmacology (Berl) 186: 612-619.

O'Brien CP (1997). A range of research-based pharmacotherapies for addiction. Science 278: 66-70.

Palmer RH, Young SE, Hopfer CJ, Corley RP, Stallings MC, Crowley TJ et al (2009). Developmental epidemiology of drug use and abuse in adolescence and young adulthood: Evidence of generalized risk. Drug Alcohol Depend 102: 78-87.

Paxinos G, Watson C (1998). The rat brain in stereotaxic coordinates. 4th edn Academic Press: San Diego, CA.

Peters J, Kalivas P, Quirk G (2009). Extinction circuits for fear and addiction overlap in prefrontal cortex. Learn Mem 16: 279-288.

Robinson TE, Gorny G, Savage VR, Kolb B (2002). Widespread but regionally specific effects of experimenter- versus selfadministered morphine on dendritic spines in the nucleus accumbens, hippocampus, and neocortex of adult rats. Synapse 46: 271-279.

SAMHSA (2012). Substance Abuse and Mental Health Services Administration, results from the 2010 National Survey on Drug Use and Health: National Findings, NSDUH Series H-42, HHS. SAMHSA: Rockville, MD, Publication No. (SMA) 11-4667.

Schochet T, Kelley A, Landry C (2004). Differential behavioral effects of nicotine exposure in adolescent and adult rats. Psychopharmacology (Berl) 175: 265-273.
Schochet TL, Kelley AE, Landry CF (2005). Differential expression of arc mRNA and other plasticity-related genes induced by nicotine in adolescent rat forebrain. Neuroscience 135: 285-297.

Shaham Y, Shalev U, Lu L, De Wit H, Stewart J (2003). The reinstatement model of drug relapse: history, methodology and major findings. Psychopharmacology (Berl) 168: 3-20.

Shahbazi M, Moffett AM, Williams BF, Frantz KJ (2008). Age- and sex-dependent amphetamine self-administration in rats. Psychopharmacology (Berl) 196: 71-81.

Shalev U, Morales M, Hope B, Yap J, Shaham Y (2001). Timedependent changes in extinction behavior and stress-induced reinstatement of drug seeking following withdrawal from heroin in rats. Psychopharmacology (Berl) 156: 98-107.

Shram M, Funk D, Li Z, Lê AD (2007). Acute nicotine enhances c-fos mRNA expression differentially in reward-related substrates of adolescent and adult rat brain. Neurosci Lett 418: 286-291.

Shram MJ, Funk D, Li Z, Lê AD (2008). Nicotine self-administration, extinction responding and reinstatement in adolescent and adult male rats: evidence against a biological vulnerability to nicotine addiction during adolescence. Neuropsychopharmacology 33: 739-748.

Sowell ER, Thompson PM, Holmes CJ, Jernigan TL, Toga AW (1999). In vivo evidence for post-adolescent brain maturation in frontal and striatal regions. Nat Neurosci 2: 859-861.

Spear LP (2000). The adolescent brain and age-related behavioral manifestations. Neurosci Biobehav Rev 24: 417-463.

Sturman DA, Moghaddam B (2011). Reduced neuronal inhibition and coordination of adolescent prefrontal cortex during motivated behavior. J Neurosci 31: 1471-1478.

Tseng K-Y, O'Donnell P (2007). Dopamine modulation of prefrontal cortical interneurons changes during adolescence. Cereb Cortex 17: 1235-1240.

Van den Oever M, Goriounova N, Li K, Van der Schors R, Binnekade R, Schoffelmeer ANM et al (2008). Prefrontal cortex AMPA receptor plasticity is crucial for cue-induced relapse to heroin-seeking. Nat Neurosci 11: 1053-1058. 